\title{
Diffusion of Ethylene Glycol in Solid State Poly(ethylene terephthalate)
}

\author{
K. H. Yoon, M. H. Kwon, M. H. JeOn, \\ and O. O. PARK* \\ Department of Chemical Engineering \\ Korea Advanced Institute of Science \& Technology, \\ 373-1, Kusung-Dong, Yusung, Taejon 305-701, Korea
}

(Received December 5, 1991)

\begin{abstract}
A comprehensive model considering both diffusion and reactions simultaneously was established and the diffusion coefficient of ethylene glycol, $D_{\mathrm{e}}$ was obtained by comparing with the desorption results in solid state poly(ethylene terephthalate). The diffusion coefficient of ethylene glycol, $D_{\mathrm{e}}$ was found to be proportional to the volume fraction of amorphous of poly(ethylene terephthalate) sample, and it was $5.67 \times 10^{-8} \mathrm{~cm}^{2} \mathrm{~s}^{-1}$ at $230^{\circ} \mathrm{C}, \chi_{\mathrm{c}}=0.373$, which is slightly higher than reported elsewhere. ${ }^{8}$ The activation energy for diffusion in solid state poly(ethylene terephthalate) was $28 \mathrm{kcal} \mathrm{g}^{-1} \mathrm{~mol}^{-1}$.
\end{abstract}

KEY WORDS Diffusion Coefficient / Solid State Polymerization Ethylene Glycol / Poly(ethylene terephthalate) / Crystallinity /

It is well known that most physical and mechanical properties of polymers can be improved as their molecular weights increase. This is why many efforts have been focused to synthesize particulary high molecular weight of poly(ethylene terephthalate) (PET). In the melt condensation polymerization of PET, molecular weights of about 30000 are hardly exceeded, and the melt becomes too viscous to be discharged from the reactor as reactions proceed. Therefore solid state polymerization (SSP) is usually employed to increase the molecular weight further, even though it takes somewhat long time.

Polymers produced by SSP often have improved properties because side reactions leading to defects in the chemical structure can be limited or avoided due to the low temperature operation $\left(220-250^{\circ} \mathrm{C}\right)$. At these temperatures the functional groups are sufficiently mobilized to give a reversible reaction forward in which byproducts like ethylene glycol (EG) are released. To build up longer molecular chains, the removal of byproducts is essential. It involves diffusion of the byproduct through the PET particle and desorption from the particle surface. Understanding of the diffusion of small molecules through solid state PET is necessary to design a SSP reactor.

Considerable efforts have been directed at elucidating diffusion in polymers where the diffusing substrate is inert toward the medium. However, it has not been well understood when diffusion is accompanied by chemical reactions. For the complete description of SSP the chemical reactions as well as the diffusion of the byproducts should be taken into account. But, it becomes extremely difficult to obtain any meaningful data owing to the coupling effects of both diffusion and chemical reactions. So, a suitable model for the reaction-diffusion system should be first established to obtain the

\footnotetext{
* To whom all correspondence should be addressed.
} 
proper diffusivity.

The diffusion coefficient of EG in the melt state PET was successfully obtained and reported elsewhere. ${ }^{1}$ Here we are aiming to obtain the diffusion coefficient of EG in the solid state PET from the desorption experiment with the intention of quantitative analysis of solid state PET polymerization process.

\section{FACTORS AFFECTING SSP}

Temperature is probably one of the most important factor in SSP due to its interrelation with almost all other aspects of the process. Increasing temperature usually results in an increase of overall rate of the process as consequence of the increment in both reaction and diffusion rates. Too low temperature requires too long reaction time, but higher temperature, on the other hand, favor undesired side reactions and may cause problems connected with particle sticking. Commonly, SSP is carried out at a temperature close to the melting point of the polymer $\left(10-40^{\circ} \mathrm{C}\right.$ lower), which means $220-250^{\circ} \mathrm{C}$ for PET. It may be convenient to preheat the polymer for drying, which helps to avoid sticking by enhancing the crystallinity. However the degree of crystallinity may retard the diffusion of the byproducts since it is very hard for small molecules to diffuse through the crystallized region. It was also noted that the apparent rate constants are higher than those expected from extrapolation of the melt polymerization values, as a consequence of the higher concentration of end groups in the amorphous region. It was reported SSP is controlled by diffusion when the PET particle size is greater than 100 mesh and the temperature is higher than $210^{\circ} \mathrm{C}$ whilst at a lower temperature $\left(160^{\circ} \mathrm{C}\right)$ the reaction becomes the rate-controlling step. ${ }^{2}$ In the temperature range of $160-210^{\circ} \mathrm{C}, \mathrm{SSP}$ is controlled by both diffusion and reaction. However, it is clear that even above $210^{\circ} \mathrm{C}$ the reactions can not be totally neglected since reversible condensation reactions are not at equilibrium at any instance due to the deficiency of byproducts. In this study, the diffusion coefficient of EG will be measured at the temperature range of $230-245^{\circ} \mathrm{C}$ with PET samples varying its crystallinity.

\section{MATHEMATICAL MODEL}

Various reactions occur in solid state polymerization of PET. These consist of the depolymerization reaction and side reactions forming side products such as acetaldehyde, DEG and water. They are summarized as follows ${ }^{3}$ :

\section{Reaction Schemes}

1. Depolymerization reaction:

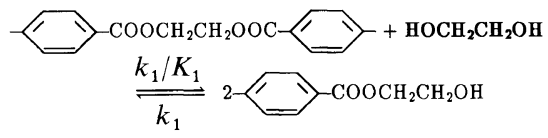

2. Acetaldehyde formation reactions:

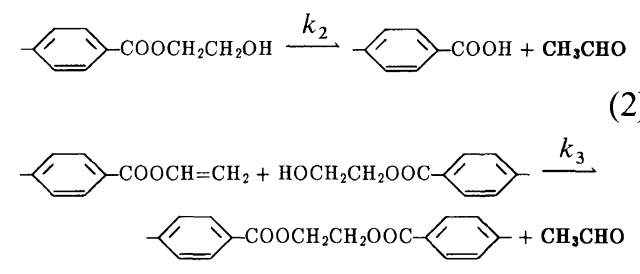

3. Water formation reactions:

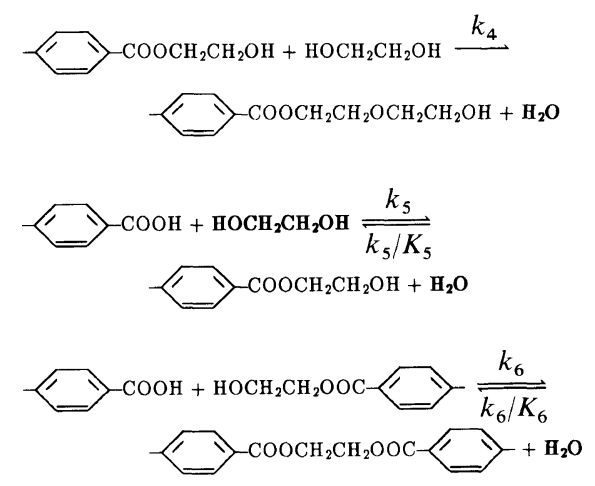

4. Diethylene glycol (DEG) formation reaction: 


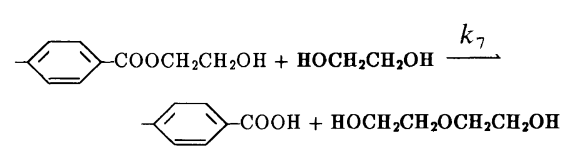

5. Diester group degradation reaction:

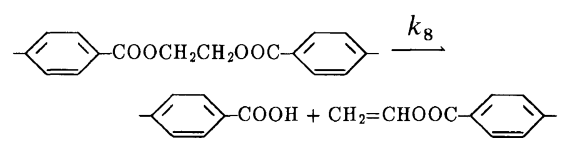

\section{Derivation of the Mass Balance Equations}

The shape of PET sample for modeling is assumed to be spherical as shown in Figure 1. Individual mass balance equations of suggested reaction schemes $1-8$ are as follows:

$$
\begin{aligned}
& \frac{\mathrm{d} P}{\mathrm{~d} t}=R_{1}+R_{3}+R_{6}-R_{8} \\
& \frac{\mathrm{d} P_{\mathrm{h}}}{\mathrm{d} t}=2 R_{1}-R_{2}-R_{3}-R_{4}+R_{5}-R_{6}-R_{7} \\
& \frac{\mathrm{d} P_{\mathrm{a}}}{\mathrm{d} t}=R_{2}-R_{5}-R_{6}+R_{7}+R_{8} \\
& \frac{\mathrm{d} P_{\mathrm{v}}}{\mathrm{d} t}=-R_{3}+R_{8} \\
& \frac{\mathrm{d} C_{\mathrm{e}}}{\mathrm{d} t}=D_{\mathrm{e}}\left[\frac{\partial^{2} C_{\mathrm{e}}}{\delta r^{2}}+\frac{2}{r} \frac{\partial C_{\mathrm{e}}}{\partial r}\right]-R_{1}-R_{4}-R_{5}-R_{7} \\
& \frac{\mathrm{d} C_{\mathrm{w}}}{\mathrm{d} t}=D_{\mathrm{w}}\left[\frac{\partial^{2} C_{\mathrm{w}}}{\partial r^{2}}+\frac{2}{r} \frac{\partial C_{\mathrm{w}}}{\partial r}\right]+R_{4}+R_{5}+R_{6}
\end{aligned}
$$$$
\frac{\mathrm{d} C_{\mathrm{a}}}{\mathrm{d} t}=D_{\mathrm{a}}\left[\frac{\partial^{2} C_{\mathrm{a}}}{\partial r^{2}}+\frac{2}{r} \frac{\partial C_{\mathrm{a}}}{\partial r}\right]+R_{2}+R_{3}
$$

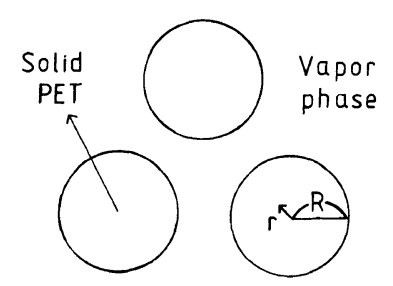

Figure 1. The geometry of PET sample used for desorption.

$$
\frac{\mathrm{d} C_{\mathrm{g}}}{\mathrm{d} t}=D_{\mathrm{g}}\left[\frac{\partial^{2} C_{\mathrm{g}}}{\partial r^{2}}+\frac{2}{r} \frac{\partial C_{\mathrm{g}}}{\partial r}\right]+R_{4}+R_{7}
$$

Here $D_{\mathrm{e}}, D_{\mathrm{w}}, D_{\mathrm{a}}$, and $D_{\mathrm{g}}$ are the diffusion coefficient of EG, water, acetaldehyde and diethylene glycol (DEG), respectively. $P, P_{\mathrm{h}}$, $P_{\mathrm{a}}, P_{\mathrm{v}}, C_{\mathrm{e}}, C_{\mathrm{w}}, C_{\mathrm{a}}$, and $C_{\mathrm{g}}$ represent the concentrations of polymer, hydroxyl end group, acid end group, vinyl end group, EG, water, acetaldehyde, and DEG, respectively. Note that the total content of DEG (free DEG and DEG incorporated in the polymer chain) is calculated and therefore the material balance equations for free DEG and DEG incorporated in the polymer chain are not written separately.

Overall reaction rates for reactions (1)-(8) can be written as follows:

$$
\begin{aligned}
& R_{1}=k_{1}\left[4\left(P_{\mathrm{im}}-P\right) C_{\mathrm{e}} / K_{1}-P_{\mathrm{h}}^{2}\right] \\
& R_{2}=k_{2} P_{\mathrm{h}} \\
& R_{3}=k_{3} P_{\mathrm{v}} P_{\mathrm{h}} \\
& R_{4}=k_{4} P_{\mathrm{h}} C_{\mathrm{e}} \\
& R_{5}=k_{5}\left(P_{\mathrm{a}} C_{\mathrm{e}}-P_{\mathrm{h}} C_{\mathrm{w}} / K_{5}\right) \\
& R_{6}=k_{6}\left(P_{\mathrm{a}} P_{\mathrm{h}}-P C_{\mathrm{w}} / K_{6}\right) \\
& R_{7}=k_{7} P_{\mathrm{h}} C_{\mathrm{e}} \\
& R_{8}=k_{8}\left(P_{\mathrm{im}}-P\right)
\end{aligned}
$$

where $P_{\text {im }}$ is the hypothetical initial monomer concentration and $k_{\mathrm{i}}(i=1-8)$ is the reaction rate constants and $K_{1}, K_{5}, K_{6}$ are the reaction equilibrium constants.

The initial and boundary conditions for solving the material balance equations are as follows:

$$
\begin{aligned}
& P=P_{0}, \quad C_{\mathrm{e}}=C_{\mathrm{e} 0} \\
& P_{\mathrm{h}}=P_{\mathrm{h} 0}, \quad C_{\mathrm{w}}=C_{\mathrm{w} 0} \\
& P_{\mathrm{a}}=P_{\mathrm{a} 0}, \quad C_{\mathrm{a}}=C_{\mathrm{a} 0} \\
& P_{\mathrm{v}}=P_{\mathrm{v} 0}, \quad C_{\mathrm{g}}=C_{\mathrm{g} 0}, \quad t=0, \quad 0 \leq r \leq R \\
& \frac{\partial P}{\partial r}=\frac{\partial P_{\mathrm{h}}}{\partial r}=\frac{\partial P_{\mathrm{a}}}{\partial r}=\frac{\partial P_{\mathrm{v}}}{\partial r}=0, \\
& C_{i}=0, \quad(i=\mathrm{e}, \mathrm{w}, \mathrm{a}, \mathrm{g}) \quad t>0, \quad r=R
\end{aligned}
$$




$$
\begin{aligned}
& \frac{\partial P}{\partial r}=\frac{\partial P_{h}}{\partial r}=\frac{\partial P_{\mathrm{a}}}{\partial r}=\frac{\partial P_{\mathrm{v}}}{\partial r}=0 \\
& \frac{\partial C_{i}}{\partial r}=0, \quad(i=\mathrm{e}, \mathrm{w}, \mathrm{a}, \mathrm{g}) \quad t>0, \quad r=0
\end{aligned}
$$

where the subscript 0 represents the initial concentration of respective species and $C_{i}(i=\mathrm{e}$, $\mathrm{w}, \mathrm{a}, \mathrm{g}$ ) represents the concentration of volatile materials. The diffusive molar flux of volatile materials is given by;

$$
F_{\text {output }, i}=\left.\int_{0}^{t} D_{i} \frac{\partial C_{i}}{\partial r}\right|_{r=R} \mathrm{~d} t \quad(i=\mathrm{e}, \mathrm{w}, \mathrm{a}, \mathrm{g})
$$

where $F_{\text {output }, i}$ represents the molar flux of volatile materials. The net mass uptake per unit mass of PET, $M_{\mathrm{t}}$ is then give by

$$
M_{\mathrm{t}}=\sum_{i} F_{\text {output }, i} M_{i} / \rho R
$$

where $M_{i}, \rho$ represent the molecular weight of volatile materials and density of PET, respectively.

Basic assumptions for solving the eq 9-16 are given as follows;

1. Assumption of apparent concentration of end groups; The concentration of end groups must be modified because they locate in the amorphous region where diffusion and reaction occur.

$$
C_{\text {eff }}=\frac{C_{\text {avg }}}{1-\chi_{\mathrm{c}}}
$$

where $C_{\text {eff }}, C_{\text {avg }}$, and $\chi_{\mathrm{c}}$ are effective concentration of end groups, average concentration of end groups and crystallinity of PET particles, respectively.

2. Reactivity of a functional group does not depend upon the polymer chain length.

3. Molecular diffusion coefficient of polymeric species is much smaller compared with those of the volatile species.

\section{Values of Initial Concentrations and Kinetic}

\section{Parameters}

The initial concentration of acid end group $P_{\mathrm{a} 0}$, vinyl end group $P_{\mathrm{v} 0}$, water $C_{\mathrm{e} 0}$, and acetaldehyde $C_{\mathrm{a} 0}$ used in SSP modeling were assumed to be zero. The initial concentration of polymer $P_{0}$ can be given by ${ }^{4}$

$$
P_{\mathrm{im}}-P_{0}=(\mathrm{DP}-1) \frac{\left(P_{\mathrm{h} 0}+P_{\mathrm{a} 0}+P_{\mathrm{v} 0}\right)}{2}
$$

The initial concentration of DEG is given by the following equation as a function of melting temperature of PET. ${ }^{4}$

$$
\mathrm{Mol} \% \mathrm{DEG}=\frac{271-\text { Melting Point }\left({ }^{\circ} \mathrm{C}\right)}{3}
$$

Table I. Initial conditions used in this work ${ }^{\mathrm{a}}$

\begin{tabular}{ccccc}
\hline$P_{\mathrm{im}}$ & $P_{0}$ & $P_{\mathrm{h} 0}$ & $C_{\mathrm{e} 0}$ & $C_{\mathrm{g} 0}$ \\
\hline $4.16 \times 10^{-3}$ & $5.01 \times 10^{-5}$ & $9.90 \times 10^{-4}$ & $2.98 \times 10^{-7}$ & $2.51 \times 10^{-6}$ \\
\hline
\end{tabular}

a Initial condition of other species are assumed to be zero.

Table II. Kinetic parameters used in this work

\begin{tabular}{cccccccc}
\hline Reaction & eq 1 & eq 2 & eq 3 & eq 4, 7 & eq 5 & eq 6 & eq 8 \\
\hline $\begin{array}{c}\text { Activation energy/ } \\
\text { k cal mol }^{-1}\end{array}$ & 18.5 & 29.8 & 18.5 & 29.8 & 17.6 & 17.6 & 37.8 \\
$\begin{array}{c}\text { Frequency factor/ } \\
\text { cm }^{3} \text { mol }^{-1} \text { min }^{-1}\end{array}$ & $1.36 \times 10^{9}$ & $8.32 \times 10^{3 \mathrm{a}}$ & $3.56 \times 10^{10}$ & $8.32 \times 10^{10}$ & $2.08 \times 10^{9}$ & $2.08 \times 10^{9}$ & $7.2 \times 10^{9 \mathrm{a}}$ \\
\begin{tabular}{c} 
Equilibrium constant \\
\hline
\end{tabular} & 0.5 & - & - & - & 2.5 & 1.25 & - \\
\hline
\end{tabular}

a $\min ^{-1}$ 
The initial concentration of other species are listed in Table I. The kinetic parameters used here are listed in Table II, which were taken from reference ${ }^{3}$ except two frequency factors for $k_{2}$ and $k_{3}$. The reason is that these two parameters were most sensitive to determine the overall desorption profiles. Similar procedure is well explained in our recent work. ${ }^{1}$

\section{Diffusivity}

There are four diffusion coefficients $D_{\mathrm{e}}, D_{\mathrm{w}}$, $D_{\mathrm{a}}$, and $D_{\mathrm{g}}$ in the current model. The diffusion coefficient of water, $D_{\mathrm{w}}$ is given by the following eq $33,34^{5}$ as a function of temperature and crystallinity of PET:

$$
\begin{gathered}
\log D_{\mathrm{w}, \mathrm{a}}=-\frac{5101.3}{2.3}\left(\frac{1}{T(K)}-\frac{1}{435}\right)-4.0 \\
D_{\mathrm{w}}=D_{\mathrm{w}, \mathrm{a}}\left(1-\chi_{\mathrm{c}}\right)
\end{gathered}
$$

where $D_{\mathrm{w}}, D_{\mathrm{w}, \mathrm{a}}$ represent the diffusion coefficient of water in semi-crystalline PET and amorphous PET. In order to determine the diffusion coeficient of DEG $\left(D_{\mathrm{g}}\right)$, melting temperatures of PET samples were measured before and after desorption for a given times. These temperatures are known to the closely related to the DEG content of PET as shown in Eq. 32. The amount of DEG desorbed can be calculated accordingly and compared with model prediction by guessing appropriate value of $D_{\mathrm{g}}$. The melting point of PET was determined by differential scanning calorimeter (DSC). The values of $D_{\mathrm{g}}$ obtained by this method are shown in Table III.

The diffusion coefficients of EG, $D_{\mathrm{e}}$, and acetaldehyde, $D_{\mathrm{s}}$ can be adjustably determined by comparing the modeling with the desorption results as shown in Figure 3 , once $D_{\mathrm{w}}$ and $D_{\mathrm{g}}$ and fixed at a given temperature.

\section{EXPERIMENTAL}

\section{Materials}

PET specimens were obtained from Aldrich Chemical Co. The initial PET used is char-
Table III. $D_{\mathrm{g}}$ values obtained from experiments

\begin{tabular}{cccc}
\hline Temperature $/{ }^{\circ} \mathrm{C}$ & 230 & 240 & 245 \\
$D_{\mathrm{g}} \times 10^{9} / \mathrm{cm}^{2} \mathrm{~s}^{-1}$ & 3.70 & 12.03 & 23.67 \\
\hline
\end{tabular}

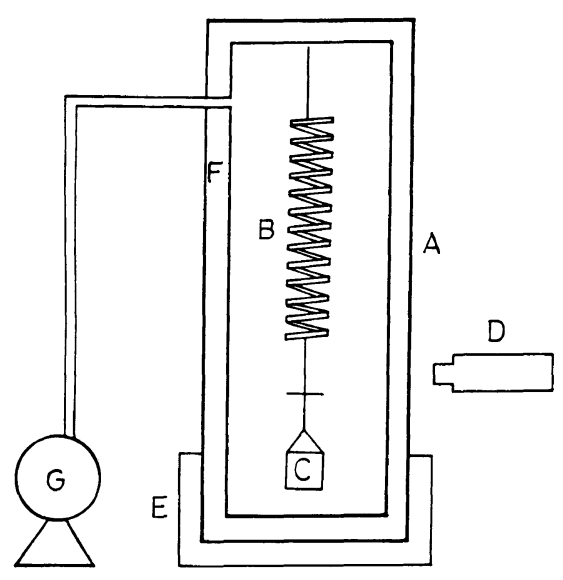
A : Sorption Chamber
B : Quartz Spring
C : Sample Holder
D : Cathetometer
E : Heater
F : Oil Jacket
G : Vacuum Pump

Figure 2. Schematic diagram of desorption apparatus.

acterized by inherent viscosity $(I V=0.54)$ and the number average molecular weight of PET samples $\left(M_{n}=14700\right)$ were calculated by the following equation. ${ }^{6}$

$$
[\eta]=7.5 \times 10^{-4} M_{n}^{0.68}
$$

The melting temperature of PET samples were $256^{\circ} \mathrm{C}$, which was obtained from differential scanning calorimeter (DSC). For SSP experiments, PET chips were ground in a high speed grinder before passing through a set of ASTM standard sieves. The small particles obtained are irregularly shaped, but can be assumed to be close to spheres. The size of PET particles used is $100-50$ mesh $(0.149-0.297 \mathrm{~mm})$. The density of PET is measured by pycnometer with the accuracy of $+0.004 \mathrm{~g} \mathrm{~cm}^{-1}$. The crystallinity of PET particles was calculated by the desity of PET. 


$$
\chi_{\mathrm{c}}=\frac{\rho-\rho_{\mathrm{a}}}{\rho_{\mathrm{c}}-\rho_{\mathrm{a}}}=\frac{\rho-1.335}{1.501-1.335}
$$

where $\rho_{\mathrm{a}}, \rho_{\mathrm{c}}$ represent the densities amorphous and crystalline PET, respectively.

\section{Desorption Apparatus}

The desorption apparatus is shown in Figure 2. The rate of mass loss of PET particles due to the desorption of the volatile species was measured. The weight lost was calculated by detecting the length of quartz spring. The quartz spring was manufactured by RUSKA Instruments to give us the maximum extension of $500 \mathrm{~mm}$ and its corresponding maximum weight of $1 \mathrm{~g}$. The change of spring length was observed through a Cathetometer with the accuracy of $10^{-4} \mathrm{~cm}$. Temperature of the polymer sample is controlled by means of liquid jacket filled with the silicone oil. Temperature of the silicone oil is maintained within the deviation of $\pm 0.5^{\circ} \mathrm{C}$.

\section{EXPERIMENTAL PROCEDURES}

\section{Crystallization Step}

i) The temperature of the chamber (A) was raised to the desired crystallization temperature (170, 180, 190, and $\left.205^{\circ} \mathrm{C}\right)$.

ii) PET particles in the sample holder (C) were suspended by the quartz spring inside the chamber.

iii) Then, pressure of the chamber was reduced to the low pressure range ( $1-2$ Torr) by the vacuum pump and the samples were crystallized for $1 \mathrm{~h}$.

\section{Desorption Step}

iv) The temperature of the chamber was raised to the desired desorption temperature (230, 240, and $245^{\circ} \mathrm{C}$ ).

v) When the temperature of the chamber reached the desired one, the mass loss of the PET particles was measured as a function of time for $5 \mathrm{~h}$.

\section{RESULTS AND DISCUSSION}

\section{Effect of Crystallinity}

The crystallinity of PET sample is shown in Table IV with different crystallization conditions. The crystallization rate was fastest at $190^{\circ} \mathrm{C}$ and reduced at temperature above $190^{\circ} \mathrm{C}$, which is consistent with the results of other investigator ${ }^{7}$. Figure 3 shows the dependence of crystallinity of PET sample upon the desorption curves. The net mass loss of byproducts during desorption increases as the crystallinity decreases. The diffusion coefficients of EG, $D_{\mathrm{e}}$, and acetaldehyde, $D_{\mathrm{a}}$ obtained from Figure 3 are presented graphically in Figures 4 and 5 with crystallinity. It shows that the diffusion coefficient of EG, $D_{\mathrm{e}}$ is linearly proportional to the volume fraction of the smorphous phase in PET, and can be

Table IV. Crystallinity of PET sample

\begin{tabular}{ccccc}
\hline $\begin{array}{c}\text { Crystallization } \\
\text { temperature } /{ }^{\circ} \mathrm{C}\end{array}$ & 170 & 180 & 190 & 205 \\
$\begin{array}{c}\text { Density of } \mathrm{PET} \\
\text { sample, } \rho\end{array}$ & 1.371 & 1.385 & 1.397 & 1.338 \\
\begin{tabular}{c} 
Crystallinity, $\chi_{\mathrm{c}}$ \\
\hline
\end{tabular} & 0.217 & 0.301 & 0.373 & 0.307 \\
\hline
\end{tabular}

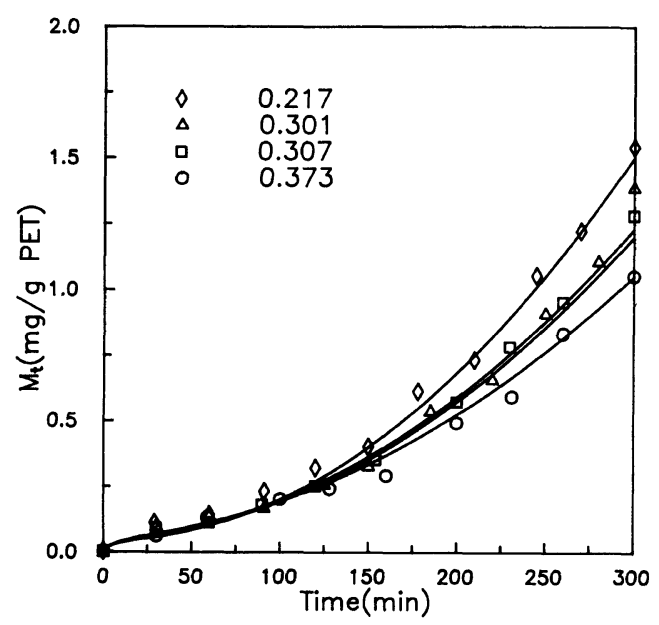

Figure 3. Desorbed amount of volatile materials for PET. (Data points are experimentally obtained at $230^{\circ} \mathrm{C}$ for PET samples with different crystallinities and solid lines are from model prediction.) 


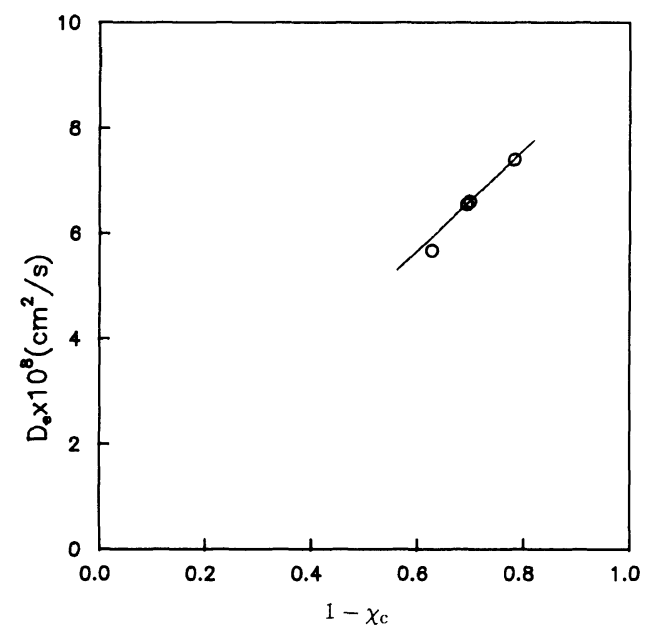

Figure 4. $D_{\mathrm{e}}$ with respect to crystallinity at $230^{\circ} \mathrm{C}$.

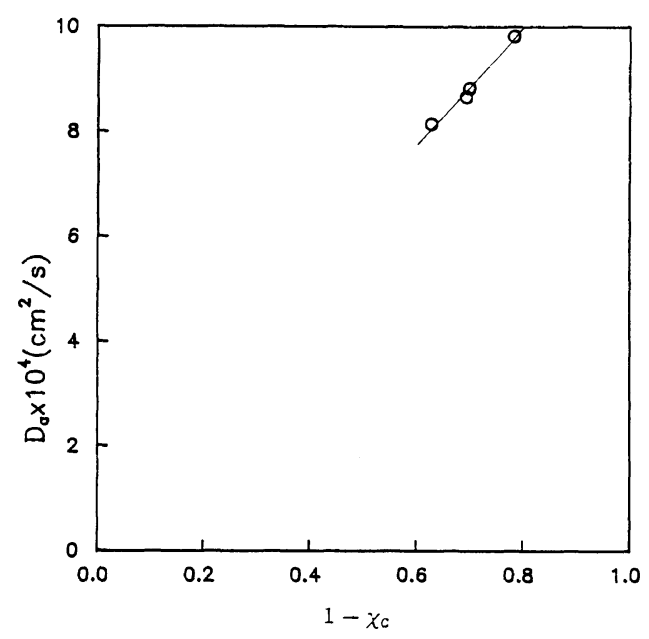

Figure 5. $D_{\mathrm{a}}$ with respect to crystallinity at $230^{\circ} \mathrm{C}$.

extrapolated to zero at $\chi_{\mathrm{c}}=1$, which was already suggested by Chang. ${ }^{8}$

\section{Effect of Temperature}

Figure 6 shows the dependence of temperature upon the desorption curves. As the temperature is increased overall rate of the process is promoted as a consequence of the increment in both reaction and diffusion rates. The value of $D_{\mathrm{e}}$ was obtained by fitting the modeling and experimental results and is shown in Figure 7 in comparison with that of

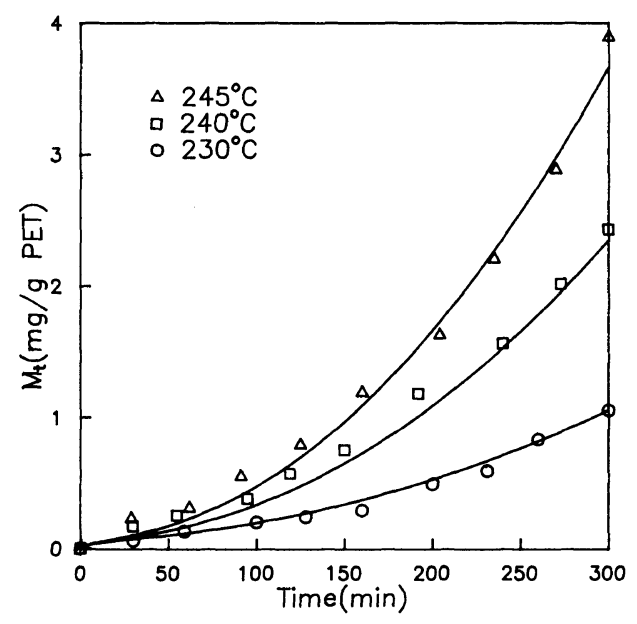

Figure 6. Desorbed amount of volatile materials for PET as function of time. (Data points are experimentally obtained at three different temperatures at $\chi_{\mathrm{c}}=0.373$. Solid lines are from corresponding model predictions.)

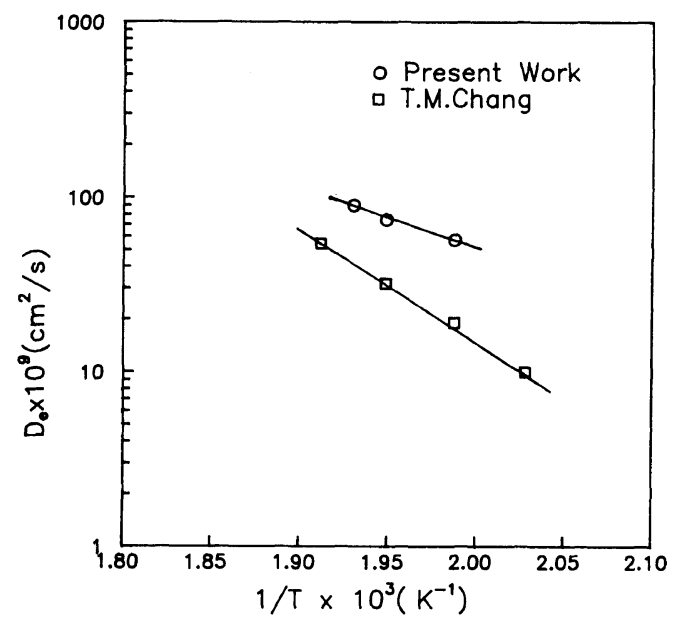

Figure 7. The diffusion coefficient of EG, $D_{\mathrm{e}}$ vs. $1 / T$. $\left(\chi_{\mathrm{c}}=0.373\right.$ for present work, while amorphous PET was used by Chang. ${ }^{8}$ )

other study ${ }^{8}$ in the form of an Arrhenius-type plot. The diffusion coefficients obtained here are slightly higher than others and the activation energy for desorption calculated from Figure 7 is found to be $28 \mathrm{kcal} \mathrm{g}^{-1} \mathrm{~mol}^{-1}$, which is smaller than that of Chang ( $30 \mathrm{kcal}-$ $\left.\mathrm{g}^{-1} \mathrm{~mol}^{-1}\right)$. 


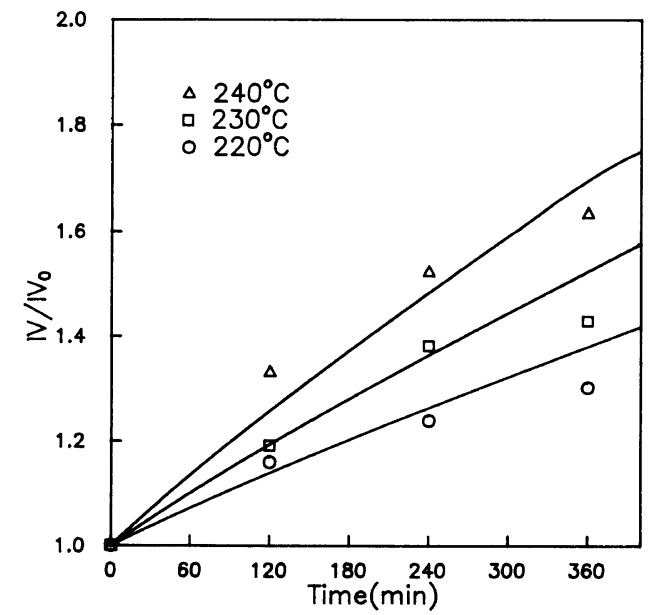

Figure 8. Inherent viscosity ratio vs. time (assumed $\chi_{\mathrm{c}}=0.373$ ). (Experimental data are taken from reference ${ }^{9}$ and compared with model prediction. Solid lines are obtained from our model along with eq. 31 and 35 with appropriate kinetic parameters and diffusion coefficients.)

\section{Comparison with Other Study}

Chang ${ }^{8}$ obtained the diffusion coefficient of EG $\left(D_{\mathrm{e}}=1.89 \times 10^{-8} \mathrm{~cm}^{2} \mathrm{~s}^{-1}\right)$ at $230^{\circ} \mathrm{C}$ in amorphous PET. He obtained the diffusion coefficient of EG by fitting the experimental DP with the modeling, where he did not account for any reactions. In this study, the diffusion coefficient of $E G$ is found to be $5.67 \times 10^{-8} \mathrm{~cm}^{2} \mathrm{~s}^{-1}$ at $230^{\circ} \mathrm{C}, \chi_{\mathrm{c}}=0.373$, which is slightly larger than that of Chang. ${ }^{8}$

The reason is that, in his model, the EG reduction by several reactions is not considered so that the amount of EG desorbed from the PET is underestimated. Therefore, the smaller value of $D_{\mathrm{e}}$ was obtained than ours. However, the deviation of $D_{\mathrm{e}}$ between two studies is not so large.

Our model with corresponding $D_{\mathrm{e}}$ obtained was applied to the experimental data in and the results are shown in Figure 8. Initial inherent viscosity of the sample used in our study is 0.54 and that in ref $^{9}$ is 0.63 . Hence, in other to compare these studies, experimental data in reference was fitted as the ratio of intrinsic viscosities $\left(I V / I V_{\mathrm{o}}\right)$ based on initial
$I V_{\mathrm{o}}=0.63$. The sample $(I V=0.63)$ used there was crystallized at $110^{\circ} \mathrm{C}$ for a long time, but the crystallinity was not given specifically. Therefore the crystallinity was assumed to be 0.373 for best fit.

Overall increasing pattern of inherent viscosities can be predicted, but detailed data are not well fitted.

\section{CONCLUSIONS}

The understanding of diffusion of small molecules has a great importance in designing polymerization reactors, but is becomes extremely difficult to obtain any meaningful data owing to the mutual effects of both diffusion and chemical reactions. So in this work, we have tried to decouple the diffusion from reaction effect by establishing an appropriate model to obtain the diffusion coefficient of EG, $D_{\mathrm{e}}$ in solid state PET by comparing the modeling with experimental results for desorption. Obtained $D_{\mathrm{e}}$ is $5.67 \times 10^{-8} \mathrm{~cm}^{2} \mathrm{~s}^{-1}$ at $230^{\circ} \mathrm{C}, \chi_{\mathrm{c}}=0.373$ and the activation energy for diffusion is $28 \mathrm{kcal} \mathrm{g}^{-1} \mathrm{~mol}^{-1}$

An established model with proper diffusivity obtained were successfully applied to explain overall solid state polymerization profiles.

\section{REFERENCES}

1. K. J. Lee, D. Y. Moon, O. O. Park, and Y. S. Kang, J. Polym. Sci., Polym. Phys. Ed., 30, 707 (1992).

2. S. Chang, M. F. Shen, and S. M. Chen, J. Appl. Polym. Sci., 28, 3289 (1983).

3. K. Ravindranath and R. A. Mashelker, AIChE J., 30, 415 (1984).

4. J. Brandrup and E. H. Immergut, "Polymer Handbook," 3rd ed, John Wiley, New York, N. Y., 1989.

5. D. W. Van Krevelen, "Properties of Polymers, "2nd ed, Elsevier, Amsterdam, 1976.

6. S. A. Jabarin, Polym. Eng. Sci., 24, 376 (1984).

7. W. H. Cobbs, Jr. and R. L. Burton, J. Polym. Sci., 10, 275 (1953).

8. T. M. Chang, Polym. Eng. Sci., 10, 364 (1970).

9. S. A. Jabarin and E. A. Lofgren, J. Appl. Polym. Sci., 32, 5315 (1986). 